\section{The Management of hybrid libraries}

\author{
Lyndon Pugh
}

\section{The Author}

Lyndon Pugh is currently teaching in the Department of Information Studies, University of Wales Aberystwyth Business School. He is the Managing editor of the Multimedia Information \& Technology journal, previously managing editor of Ariadne. Has written and researched widely on information services management.

\begin{abstract}
This research investigates managerial attitudes to some key ideas concerning the organisational design of hybrid libraries. It establishes the general theoretical base for the management of organisations operating in similar circumstances, and considers the treatment of hybrid libraries in the literature of librarianship. A questionnaire administered to UK library directors obtained responses to the key areas of organisational structures, communication, the management of electronic/digital information, skills, learning and development, teams, leadership and the degree of change in the roles of senior and middle management.
\end{abstract}

\section{The Occasion}

This research was funded by the LIRG/Elsevier Research Award.

\section{The Background}

This small scale research project has its genesis in a prolonged interest in the development of innovative management practices in information services, encompassing several studies over a period of some 13 years (Pugh, 1990, 1997, 2002). There is a broad consistency in the findings, leading to the conclusions that while managers see some merit in new approaches to managing information services, the actual implementation of novel principles is limited, and the degree of organisational change is small. This is not to gainsay the genuine innovation which has taken place, but observations of practice, and discussions with colleagues over the years also tended to confirm a degree of confusion and uncertainty surrounding some of the key ideas.

The argument explored in the research was that technological advance, and not least the consolidation and refinement of hybrid library concepts stemming from digitisation, had created circumstances which supported innovative management. Developments in creative industries and other parts of the knowledge or information sector confirmed the possibilities of applying new ideas, but these ideas tended to be ill-developed or ignored in information services. The objective was therefore to examine the extent of changes in

- Organisational structures

- Communication

- The integration of conventional and electronic material in libraries

- Leadership and management styles

- Skills development and organisational learning

- Teamwork

- Role changes

\section{Aims and Objectives}

1. To identify a theoretical basis for the management of hybrid libraries

2. To establish current practice in hybrid library management, in terms of the features identified above

3. To develop a model of hybrid library development

4. To identify areas of further investigation 


\section{Some Limitations}

As indicated above, the research is small scale, and although the response to the questionnaire was statistically valid, the rate was lower than those of the earlier studies. It is clearly not a longitudinal study, and no detailed statistical correlations were carried out.

The purpose was simply to establish some easily understandable general indications of what managers thought they were doing in the context of hybrid libraries, and to provide some pointers to areas for further and more detailed study. The population was made up of senior staff, and the results are therefore a snapshot of managerial views at a particular stage in the development of digitised collections. The views of staff below managerial level were not sought, so the results cannot be treated as a commentary on the organisational health of libraries in general.

However, the previous research of the author tended to indicate that the different perspectives of staff below senior management led to a divergence of views on the nature of managerial behaviour. This was particularly true of the degree of decentralisation or devolution of power, the efficacy of consultation and shared decision-making, communication and the reduction of bureaucracy and organisational layers. Staff below management level often saw these features as being less widespread, and much weaker, than they appeared to management. This opens up the possibility that organisations might in fact be far more traditional in reality than even the research findings indicate. A comparison of attitudes to management practices in hybrid libraries seems to be a potentially fruitful area to investigate.

\section{A Review of the Literature}

In part, the researcher's view of hybrid library management in practice was coloured by what appeared to be an imbalance in the literature of library management. This could be characterised by:

- A weak debate about the managerial implications of the organisational change in the context of digital information resources alongside conventional resources; ie the managerial implications of hybrid libraries

- A disparity between the way in which the organisational implications of technological change are covered in the literature of management in general, and the treatment of the same area in the professional literature.

- The resultant possibility of a gulf between the practice of management in hybrid library services and the management approach evident in other organisations facing similar issues and problems in non-information sectors.

- A consequent absence of comprehensive models for the organisational development of hybrid libraries

Against this background, the literature review set out to:

- Identify the main theoretical preoccupations associated with the development of hybrid libraries

- Set these against emerging considerations in mainstream management theory

- Provide the theoretical basis of an organisational model for hybrid libraries

The literature of hybrid libraries is characterised by

- A technological bias

- A tendency to reportage, seen in a major concentration on repetitive analysis of digitisation projects

- An accompanying emphasis on the mastery and application of technical skills to do with ICT, the development of economic models, and technical issues to do with document analysis and description. This appears to largely exclude the human aspects of information services development and management.

- Alongside the general literature of management, the preoccupation with technological issues seems to isolate librarianship from the impact of novel management theories which might offer some profitable avenues for the exploration of new concepts of library organisation.

It is possible, but tedious, to provide a detailed cornucopia of references to support these 
propositions. Section One of the full report of the research project (LIRG, 2004), and the bibliography, contain more detailed comment and full references. The literature review also identified other writes who had collectively laid down some considerations which could form the basis of a more comprehensive model of hybrid library management.

\section{The Model}

From the literature review, it was possible to identify the key characteristics of today's information services, partly from the emphasis on technology, and partly from the strictures of writers such as Feather and others. Libraries are

- Technologically driven

- Based on a combination of traditional and electronic services, and with a need to translate this into new forms of service delivery

- Complex

- Volatile and unpredictable

- Demanding new skills, and new combinations of old and new skills

- Facing a need to work with physically remote users

- Facing structural change, although the firm evidence of structural change on the ground is not yet emerging (Pugh, op cit), and this is almost 30 years after similar comments by Gorman (1979).

The theoretical argument is that organisations displaying these features will ideally develop characteristics which differentiate them from what might be seen as typical traditional libraries. They will also be based on ideas and principles which differ from the traditional foundation stones of librarianship. The professional literature as yet demonstrates little acknowledgement of these requirements. By contrast there is a mass of information to be found in the general literature of management.

In the literature of management there is a welltrodden path through the theory of enlightened, non-bureaucratic management. What is lacking in librarianship is a precise identification of the conditions of contemporary organisations in relation to some of the newer theories to be found in the canon of management literature. Information services are made up of

- Librarians

- IT specialists

- Media specialists

- Graphic designers

- Web designers

- Web masters

- Members of other professions not previously associated with librarians

As organisations, they possess the potential, through the strength of their information systems and other features, to build flexible and powerful networks across organisational structures. There are three theoretical positions which are particularly relevant to modern library organisations: organisational creativity, organisational redundancy, and network analysis. These encompass ideas about organisational learning, communication, changes in managerial roles, and ultimately structural change.

\section{Creativity}

One definition of creativity, among many, is that it involves new ways of thinking, which can be applied to problem solving in novel situations where there is uncertainty and change. This itself is applicable to libraries, and so are the basic conditions which writers like Hirshberg (1998) and Morgan (1997) saw as essential for organisational creativity:

- The presence of different kinds of staff, with different traditions, ways of looking at things, training, education, priorities, and cultures

- A high level of technology

- Uncertainty

- A large number of customer-facing staff (Pasternak and Viscio, 1998)

- A commitment to learning and to the application of the results of learning in the workplace

- An effective and comprehensive communication system

Sutton (2002), argues that a different set of rules are required if organisations are to encourage creativity. These rules depend on something other than bureaucracy and conventional approaches to managing. In common with 
others, he affirms the need for creative friction, which comes from the bringing together of opposites. Hybrid libraries present the opportunity to do this, given the characteristics identified above:

If it's creativity you want, you should encourage people to ignore and defy superiors - and, while you're at it, get them to fight among themselves.

- There are also implications for leadership and for structures (Mauzy and Harriman, 2003). These writers advocate "systemic creativity" where the development of new ideas is the responsibility of everyone, rather than the preserve of a hierarchy vested with formal authority and legal power. In practice, this calls for both top-down and bottom-up change initiatives, as well as special projects.

The kind of approach advocated here contributes to the development of what has been termed "fuzziness" in the literature:

- Uncertainty over where responsibilities begin and end

- A weakening of the sense of ownership of territory

- A more permissive attitude to rules and regulations

- More accommodating and overtly supportive and educative management and leadership styles

- An organisational climate which is generally more sympathetic to enterprise and innovation.

Maletz and Nohria took up this idea in their examination of "whitespace and blackspace" (2001). Blackspace is the conventional area of operations where it is appropriate to deal in certainties: the traditional establishment of aims and objectives and the managed and systematic programmes and activities designed to achieve those objectives.

Whitespace on the other hand exists where there are uncertainties:

- Where precedent offers few guidelines

- Where there are no clear answers to problems

- Where there is more than one way of proceeding
- Where there are competing claims on the management of a project

- Where there is a more than usual degree of risk attached to an idea or a proposal.

Whitespace is therefore inhabited by managers who:

- slash red tape

- cut corners

- work outside formal channels and structures

At the same time, in other ways they work with the existing structures and parameters. Akin to thinking outside the box, this is an appropriate talent to cultivate in organisations which are made up of apparently disparate groups and interests.

In the professional literature, there are a few writers who reflect a promising mindset in reporting cross-disciplinary collaboration in the management of electronic resources in several university information services. This involves shared working between subject specialists working in different areas within the library. What is perhaps less obvious is the connection to be made with the potential benefits of a wider and more energetic collaboration. This could cross the more impermeable boundaries now existing in some modern library services, such as those between ICT services and other parts of the organisation, or between electronic and conventional collections. Further development here could contribute massively to organisational creativity. But to succeed, this approach demands a new mindset, not least because it calls for a willingness to look at power in a different way, unalloyed by territorialism:

Authority is a weapon of last resort. If you are doing your job correctly, others should be convinced by self-interest. If they resist, examine the situation for communication errors and try again. (Maletz and Nohria, op cit)

Tomke (2001) made a similar point in his championing of "enlightened experimentation". In his view, innovation depended on:

- A reassessment of the legitimacy of conventional organisational boundaries 
- Working with small teams which were selfsufficient in terms of expertise and authority

- Risk taking

- Without fear of failure but with an abhorrence of mistakes

Both of the above sources attest to the necessity of developing new management skills and attitudes. They also confirm the need for structural change to make it easier for the groups to form, and powerful communication, learning, and information systems.

\section{Organisational Redundancy}

Morgan (op cit) also advanced the argument for organisational redundancy - the capacity of an organisation to encourage the learning of new skills, even to the point where staff possess more skills than they need to carry out their immediate tasks. It means opening up the organisation's information system to put more information into the public domain, and at the disposal of individuals, than they actually need for operational purposes. In general terms, it means that each part of the organisation is possessed of more skills, more knowledge, and more responsibility than it actually needs to discharge its primary functions.

\section{Organisational Learning}

Creativity in organisations is founded on learning. It is the kind of learning which is inclusive, embracing formal and informal learning, individual and group learning. It is developmental, and aims to change the organisation by strengthening and extending the organisational knowledge base. Pearn and Mulrooney (1995) and Pearn, Roderick and Mulrooney (1995) still offer the best expositions of organisational learning, but Robbins (2003) also offers a useful template for developing organisational learning:

- Make learning a formal requirement of the job, planned and scheduled

- Inculcate learning from experience, especially learning from the decision making process

- Establish specific learning outcomes

- Provide support systems and resources
To this could be added

- Organisations which take a strategic view of learning

- Make learning inclusive, at all organisational levels

- Base learning on self-development (Bailey, 2001)

- Teach staff the principles and procedures of self-development, and how to learn from work (Pugh, 2001)

- Make it easy for the results of learning, and the acquisition of skills, to be used in the workplace - by changing structures, communication, and human resource management

\section{Knowledge Management}

Allee (2003) makes a crucial point about knowledge management, suggesting the significance of knowledge sharing, and the development of networks and relationships which help create and share knowledge in organisations. One of the issues here is that rigid organisational structures tend to inhibit the growth of networks and the spread of knowledge and information. The use of ICT to develop an information system, and the application of knowledge management to this function, will support flexible structures, organisational learning, and human resource development. Viewed from this standpoint, knowledge management will also form a component of approaches based on some of the other ideas discussed in this section: Allee (op cit) offers the idea of the organisation as a "living network", for example, and this itself carries echoes of Morgan's "organization as brain" (op cit) as well as ideas about team based structures. These ideas call for a departure from the approach Deegan and Tanner (2002) noted, which emphasised the role of knowledge management in developing technologically complex information sharing almost as an end in itself.

\section{Communication}

There is also a connection between structures and communication. Both the professional literature and the literature of general management reflect substantial interest in knowledge management as a means of 
identifying and applying the different kinds of knowledge held within various organisational levels, and in various forms. There is support for the proposal that traditional hierarchies needed to be replaced by the free flow of knowledge and information across the organization, and the positive value of comprehensive and open information exchange in organisations where devolution of responsibility is emerging.

Other relevant characteristics for information and knowledge sharing were also identified:

- Changes in managerial styles, concentrating on enabling, influencing and involvement

- Unifying structural features

- A culture which values collaboration

- Networking

- A formal commitment to knowledge sharing

- Formal interaction between departments, divisions, teams, and units

- The use of informal networks to identify and use key knowledge sources and influencers

\section{The Player Manager}

Managerial behaviour is one of the keys to the proper management of organisations displaying the characteristics of hybrid libraries, and the concept of the player manager is a central concern, largely ignored in the literature of library management but perhaps more prevalent in practice than is realized, even by its proponents. In fact, the idea was common in many primitive organisations and is indeed alive and well in many of the smallest information services. Auger and Palmer (2002) set it in context:

as more and more people became involved in knowledge work, the shortcomings of general management became more apparent. Handling the unexpected in innovative ways was the key to competitive advantage, and the interdependencies between good business decisions and creative production become obvious ... [managers must see] the whole equation by fully recognizing the increasingly interwoven nature of producing and managing. . . . An alternative . . is to extend the Player Manager concept to a model that involves all players in a team sharing the managing. This option twins the concept of empowerment with the much-posited ideas associated with network organizations.
Player managers are characterised by

- Agility and adaptability: enabling the organisation to change direction quickly

- Flexibility: working across a range of tasks-professional, managerial, technical, clerical—displaying versatility of thinking

- Multitalented: demonstrating a wide range of abilities

- Multifaceted: commanding in a range of leadership, managerial, and professional roles

- Talented in the technical execution of the key business of the organisation, while also capable of managing (Pugh, 2005)

They are also possessed of a combination of some technical ability, tactical skills, and the foresight for good strategy . Donkin (2001), sees some significant development:

Within the next twenty or thirty years we may well see the disappearance of conventional management and reporting structures, replaced by interdependent networks engaged in transactional relationships.

As far back as 1987, Lorsch and Mathias were referring to the resurgence of managers who had to take responsibility for both managerial services and professional work. The same forces which drive these ideas in general management are also at work in information services:

- Unpredictable technological change, with the potential for the use of technology as a creative management tool supporting behavioural and structural change

- Hybridity, creating a demand for both specialisation and multiskilling

- Disparate and varied demands from users who are informed and technologically competent in their own right

- High levels of staff awareness and expertise

- The emergence of less hierarchical organisations

In simple terms, the environment demands the adaptability and skills of the all-rounder. The role is that of

- The team-builder

- The developer of organisations

- The supporter of learning

- The exponent of multiple leadership 
- A symbol of values which include a commitment to performance and to people

- The cornerstone of an organisational community.

Tied in with ideas about sharing strategy and responsibility in general, this offers a possible organisational model.

\section{Structures}

Malone (2004) examined the significance of structures in contemporary and coming organisations, and laid down some basic principles. He also considered some problems. Decentralisation, in particular the downward relocation of significant responsibility, was seen to be beneficial when there is a premium on flexibility and entrepreneurial attitudes. But decentralisation of decision making needs to be balanced by a coordinated overall strategy and a common focus on the customer (or the user, in libraries).

Hierarchies are less effective in supporting creativity and in taking ideas from all parts of the organisation. Hierarchies also make it harder to reap the benefits of multiple views of problems and issues.

Organisations where there is a need for innovation are particularly receptive to a decentralised approach. Devolution also benefits management, in that it allows managers more time and scope to focus on key overall issues such as service quality. This, it could be argued, becomes even more important in the light of the increased power of the library user in a digital world; in particular the user's potential selfsufficiency or ability to use alternative suppliers of information.

Malone also identified areas where responsibility should not be devolved or decentralised:

- Where there are decisions with major resource implications

- Where there is an overwhelming need for uniformity

- Where there is significant conflict
It may well be that there is room for significant debate in this area: it does not necessarily mean there can be no decentralisation in these circumstances, but it can indicate the need for the retention of some structure in most organisations. Neither does it invalidate the case for sharing key decisions which do reflect Malone's criteria.

Cloke and Goldsmith (2002) added some flesh to the issue of decentralisation, by creating a coherent framework for structural change based on a range of ideas. They were concerned to demonstrate how organisations could equip themselves for the $21^{\text {st }}$ century through developing

- A collaborative ethos

- A network of self-managing teams

which would replace bureaucracies.

\section{Network Analysis}

No organisation can rely on the formal structure, or the formal communication system, alone. Cross and Parker (2002) assess the significance of the social network which underlies all organisational structures. This network differs markedly from the formal organisational structure and reporting mechanisms. According to these two writers, one of the keys to success for a modern, innovative, and flexible organisation is the ability to manage the underlying network and to use it in a positive way. For example, network analysis will identify individuals who wield a degree of influence and possess information which is disproportionate to their official position in the structure.

\section{A Model for the Hybrid Organisation}

Any model based on the ideas developed in this report will need to function effectively in the conditions set out earlier in this paper:

- It will have to offer both flexibility and structure

- It will also support creativity

- It will be based on a network of communications, as strong horizontally as they are vertically 
- Increasingly artificial and inappropriate internal divisions will be removed

- Flexible managerial attitudes supporting devolution and decentralisation will be important.

Coing (2001) encapsulates this in an expression of support for the idea of open management styles as a means of dealing with technological change. Improvements in efficiency, communication, and morale in the Bundestag Library are attributed to the development of these characteristics.

\section{Metaphors of Organisations}

Management theorists have conceptualised organisations in a number of ways. The history of management thought reveals models of organisational structures based on: machines, groups, networks (Glass, 1997); brains (Morgan, op cit); jazz quartets (Brickley, 2003); symphony orchestras (Drucker, 2003); opera management (Drucker, ibid); military units (Owen, 1996); biological metaphors and interlocking teams (Pugh, 1990 op cit), among others. There is a decipherable link between the degrees of organisational complexity and structural flexibility (Pugh, 2000). There are also links between: structural flexibility and the creative potential of organisations; between the extent of technological change, diversity and ambiguity on the one hand, and the strength of conventional management on the other (Pugh, 2005 op cit). Generally speaking, organisations facing complexity tend to introduce flexible structures, and the extent of diversity, ambiguity and creativity in organisations depends on the degree of structural flexibility.

Whatever the preferred metaphor which is applied to flexible organisations, the characteristics of the theoretical model remain the same:

- Power is distributed

- There is no single centre, although there may be a small managerial core

- All parts of the organisations are capable of both independent action and close collaboration
- There is an overall concept or ethos which unites

- What is delivered is a process, not a function

Considering these characteristics, the organisational form which most closely resembles this is that of the network which is depicted in Figure 1. The network is the formal system represented by communications structures and communication. Beneath this, and operating in another dimension, is a social network which is of at least equal importance. In the social network, irrespective of formal position, individuals talk to each other and influence each other on a range of issues. They communicate across formal boundaries, and talk at various levels. This network must be analysed and supported by managers who identify key individuals in the network. These will be opinion formers, experts, experienced staff, and people with status which does not come from formal authority. Their influence will extend throughout the network. It will also be possible to identify individuals in the network who are under pressure, and others who have a valuable contribution to make that is underutilized. Managers who take the time to analyse and use these networks can improve organizational performance, improve motivation and communication. These networks are in fact small, unrecognised distributed organizations.

One consideration of some importance is that the underlying organisational network also represents an alternative management structure. There will be individuals within it who win the respect and support of colleagues, irrespective of role or position, and exercise an influence. There are examples in the wider environment of organisations which actually promote a system in which individuals exercise managerial functions on the basis of the informal support they gain from others (Malone, op cit). 


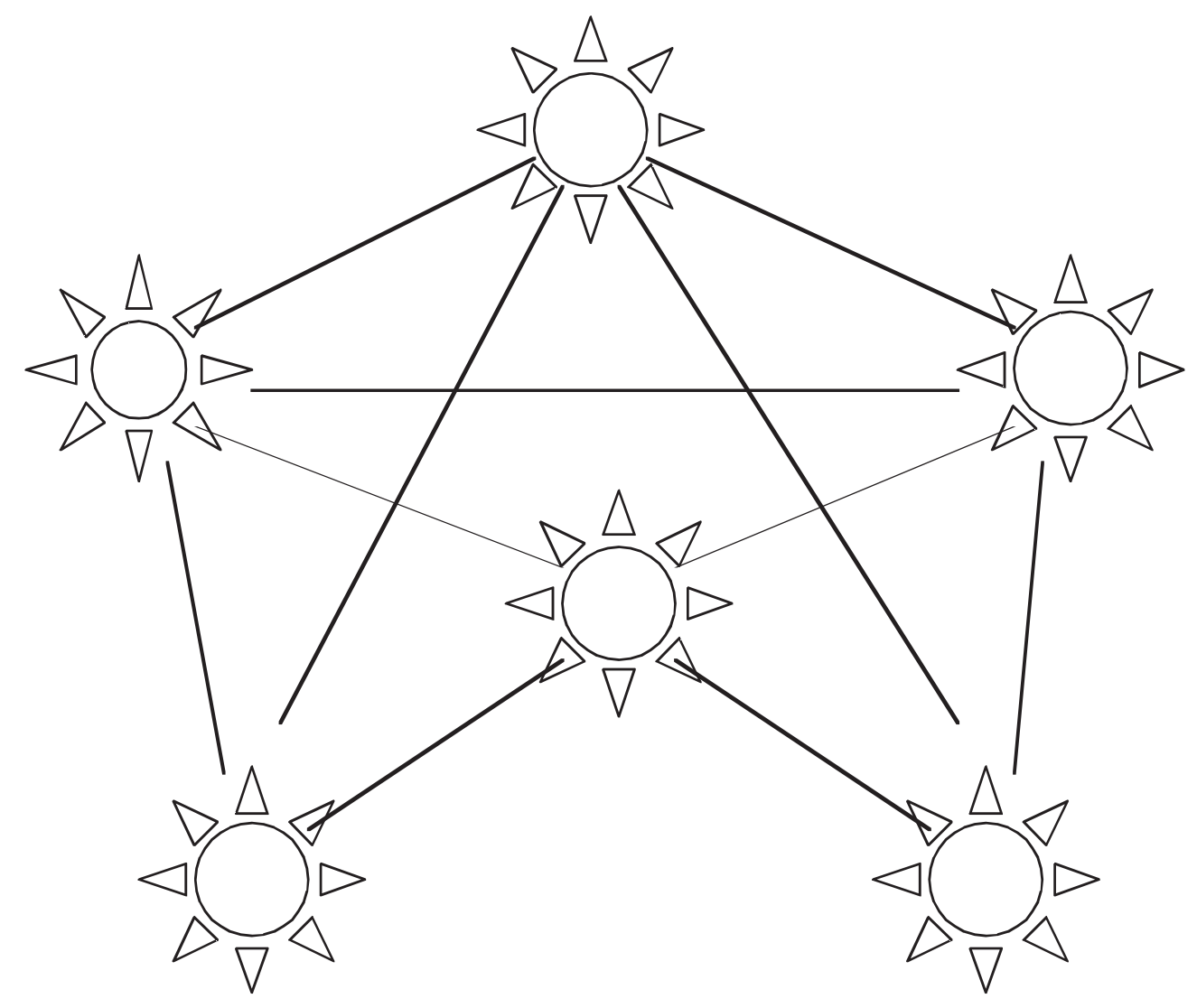

Figure 1. The Networked Organisation

\section{The Model}

The characteristics of a model of hybrid library organisation were set out in the literature review as embracing

- Distributed power

- A reduced managerial core

- Devolution and empowerment

- Process based delivery

To this can be added:

- A culture which permits and supports the questioning of accepted wisdom, because of the demands made by working in environments where traditional ways of working are no longer adequate

- The capacity to nurture cross-boundary roles in order to fully develop communication and learning, emphasising the skills of collaboration and negotiation

- Free-flowing communication

- An entrepreneurial approach to new ideas and development
- An environment which encourages inspirational leadership

The initial components of the model will be:

- A learning system

- A technological infrastructure for communication and the diffusion of information and knowledge

\section{Teams}

These requirements lead to consideration of the appropriateness of a team-based structure for hybrid library management. Management literature provides extensive detail on the characteristics of teams, and these can be summarised as:

- Appropriate for complex, unpredictable, and diverse environments

- Possessing a potential for innovative developments

- Designed to maximise individual strengths and compensate for weaknesses 
- Based on collaboration but allowing scope for independent thought

- Motivational

- Effective in high-technology environments

- Reflecting multiple leadership

- Encouraging ownership

- Based on powerful multiple communications

- Controlled by cultural and social forces, and with a unifying overall concept

\section{Operational Models}

Owen (1996 op cit, 2001) reported on the development of teams in the high-risk, hightechnology environment of aerobatics. Analysing the "unique team-building techniques" of the Royal Air Force Red Arrows, she identified:

- A selection process which not only aimed to achieve the right skills mix but also paid due attention to the appropriate mix of personalities

- The responsibility of the entire team for the selection of members

- Self-criticism as a component of individual development and as an essential part of learning

- Communication within and across teams

- The development of mutual trust

- A concern with quality

- A focus on differences - "a team should be a collection of differences."

- A match of team and personal needs

- The absence of a hierarchy

- Renewal: teams need to develop and membership needs to change

- A significant investment in learning

Many years before Owen began her in-depth analysis of teams in a military environment, that environment could have furnished evidence of similar principles in practice, embracing:

- A degree of self-selection in team formulation

- Specialisation, interchangeable roles and multiskilling

- The absence of a hierarchy

- Multiple leadership

- A massive commitment to learning and training

- Little red tape and a minimum of formal rules
- The creation of a powerful culture which could replace rules and regulations, govern behaviour and maintain the highest standards in a high-risk environment

- A dependence on the cutting edge technology of the day

To this could be added, in some environments:

- The development of an interlocking network of teams based on the specialisations of individual team members, providing linkages within a larger unit. Specialists within a team associated with equivalent specialists from other teams, exchanged information and experience, and were part of a shared learning culture.

- Powerful social networks as units lived, trained, learned and worked together as a team.

All this turned the team structure into a networked organisation.

After developing the theoretical base outlined here, the research set out to investigate how far these ideas had penetrated library management practice, given that hybrid libraries offer the optimum conditions for such ideas, and to what extent the key organisational characteristics could be discerned in the practice of library management in the hybrid library environment.

\section{Analysis}

Participants responded to a number of questions relating to

- Structures including team development

- Communication and information sharing

- The delivery of digital services

- Organisational flexibility

- Risk taking

- Organisational learning; collective and individual skills development and application

- Leadership

- The degree of change in managerial and professional roles

The following is a summary of the results in key areas: 


\section{General Issues}

Comparing returns suggests some interesting contrasts between sectors:

- Across the board, irrespective of sector, practically every manager responding considered that their organisation was developing teams. This was often accompanied by a somewhat superficial understanding of the process of creating and sustaining teams in organisations.

- The majority of managers who conceptualised their organisations as being a series of overlapping teams came from the academic sector.

- A greater percentage of public libraries than academic libraries were considered to be conventional pyramids.

- Even so, a substantial number of public libraries reported that they had flattened their organisational structures.

- Almost half of the public library sample viewed their library structures as flattened pyramids, less than one fifth considered them to be conventional, and the same percentage considered their organisations to be based on overlapping teams.

- In the academic sector, the majority of organisations reported that they were developing overlapping teams, as indicated earlier.

There are also some other general observations of note:

- Almost every response omitted some key areas from the responsibilities allocated to teams.

- Support provided for learning from work, and self-learning, frequently failed to extend beyond the provision of resources.

- There was also a surprising degree of neutrality in the perception of some key issues throughout the questionnaire, and particularly in relation to

- The relative strengths of vertical and horizontal communication

- Ease of access to senior staff

- Permissiveness with regard to the freedom of staff to try new approaches

\section{Organisational Structures}

A clear majority of respondents saw their organisational structures as flexible. This included flattened pyramids and team structures. There were a small number of matrix structures, and two nil responses. There were also a statistically insignificant number of discrete self-managing teams with a centralised managerial core, and these were confined to the academic sector. Networked organisations were identified in one case.

Neither the type of structure, nor the public/academic categorization, had any bearing on the responses to questions about teams, communication, organisational learning, leadership, skills, or role changes. This is a point of some interest. In theory, structures should influence and reflect other organisational characteristics like the openness of communications, the flow of information throughout the organisation, the managerial style, and the nature and effectiveness of teams. In none of these areas was there any significant correlation with structural types. This represents a particularly acute problem where teams are concerned, and it may be possible to draw some conclusions from the fact that team development is ostensibly being pursued in organisations which might well clearly demonstrate bureaucratic characteristics. Management literature and the professional literature both reflect some debate about this issue.

Differences between sectors were apparent in the view of organisational structures. First, substantially more managers of academic information services viewed their organisations as team structures, either self-managing or overlapping, than their counterparts in public libraries. A smaller number of public library managers viewed their organisations as conventional overall, with a majority considering their organisational shapes to be flattened pyramids. 


\begin{tabular}{|l|l|l|}
\hline & Academic Sector & Public Sector \\
\hline Conventional Pyramids & $25 \%$ & $21 \%$ \\
\hline Flattened Pyramids & $26 \%$ & $47 \%$ \\
\hline Teams & $41 \%$ & $26 \%$ \\
\hline Matrix Structures & $8 \%$ & $6 \%$ \\
\hline
\end{tabular}

Table 1: Academic/Public Differences in Structures

Flattened pyramids are achieved by removing layers, and while they are often associated with team development, almost half of the public library respondents saw their structures first as flattened rather than team-based.

Teams included both overlapping team structures and discrete self-managing teams. The number of the latter was statistically insignificant but still reflected no major organisational differences when compared with overlapping team structures. This tends to support the view that teams are at an underdeveloped stage.

A statistically insignificant number were able to demonstrate teams possessing all the necessary attributes to become real teams and to develop into self-managing teams. The most comprehensive example of team development showed a correlation between structural change and well-developed team characteristics, and also some consistent emphases in leadership and in identifying key professional skills. This response indicated an awareness of the essential components of:

- Selection

- Sustained training and development, crucially the inclusion of members with differing skills and backgrounds

- The allocation of significant power to teams

There was a second example which was heavily qualified by the size of the organisation, but which nevertheless offered instructive pointers to the key characteristics of organisation development. However, the bulk of the responses raised some issues about the true nature and purpose of team development in library organisations.
Given the above evidence of attempts to modify the affects of the bureaucracy, it would be expected that the answers to other questions would show some correlation with these reports of structural change.

Significantly, although team structures accounted for a higher percentage of organisational shapes in academic libraries as opposed to public libraries, this is as far as the difference went. In other key respects there was no significant difference between academic and public libraries as far as team development was concerned.

Turning to the recruitment, structures, training and responsibilities of teams, more inconsistencies emerge. In $25 \%$ of the teams, membership was based on staff who were in situ when the team was set up. The process whereby working groups become teams by managerial fiat, and not through a process of selection, adjustment and learning has been commented on in the literature and is an obstacle to the development of effective teams.

The degree of authority and responsibility allocated to teams is also inconsistent with the commitment to teams evinced in the identification of key skills. No more than $25 \%$ of teams possessed sufficient authority and responsibilities to provide a basis for team development and the growth of individuals.

\section{Service Delivery}

Respondents were asked to identify the ways in which electronic information was delivered to users. The options offered were:

Functional

Process

Both

Other 
The questionnaire defined the terms

"functional" and "process".

- $60 \%$ of organisations used a combination of both functional and process delivery

- $35 \%$ used purely functional delivery

- 5\% saw their organisations as being purely process-based

To be consistent with structural change, improved communications, and organisational flexibility, a larger percentage of process-based organisations would be expected.

\section{Communications}

One of the expected consequences of organisational change would be a strengthening of horizontal communications, ideally to the point where they became stronger than vertical ones. A number of respondents (40\%) reporting structural change adopted a neutral position on which of the two were stronger. In addition:

- $45 \%$ strongly disagreed that vertical communications were stronger than horizontal ones

- $15 \%$ strongly agreed that vertical communications were stronger than horizontal ones.

- $42 \%$ of respondents agreed, or strongly agreed, with the proposition that it was easy to find out what was happening throughout the organisation

- $33 \%$ felt that it was not easy

- $25 \%$ were neutral

\section{Organisational Flexibility}

The changes considered above should bring other benefits in their wake. The theoretical position indicates that modifying structures and strengthening communication across the organisation can be linked to:

- Shared strategy formulation

- Improved access to information about other parts of the organisation

- The inculcation of risk taking and the freedom to try new ideas and develop projects

- Easy access to senior management

However, $65 \%$ of respondents still felt that responsibility for strategy formulation remained with senior management, while $19 \%$ were neutral on this aspect. 16\% saw strategy formulation as being shared to a greater or lesser extent.

A clear majority of responses supported the proposition that access to senior management was easy for all staff (60\%), which would be an expected consequence of tinkering with the organisational shape, while only $25 \%$ disagreed. Once again, $15 \%$ were neutral on this issue also.

One of the characteristics of innovative organisations working in conditions of flux is the capacity to allow people to express themselves, to try new ideas and to develop new projects. The question of how easy it was to win permission to do something novel or different produced a conservative answer. $32 \%$ of respondents felt it was not easy, while practically the same percentage (31\%) felt that it was. $37 \%$ were neutral.

\section{Knowledge Management}

Respondents were asked to assess the extent to which knowledge management was practised throughout their organisations, in the context of the general approach to communication. This was linked to questions about the type of information widely available via an electronic network, and the internal communication channels used, with particular reference to communication across internal boundaries.

In academic information services, the matrix structures reported well-developed communication systems which were not matched to the same extent by other structural types in either sector. An average of 8.5 different types of documentation were made available across an electronic network, and an average of 6.25 different channels of communication acrossorganisations were identified. The same trend was established in public libraries, and organisations with conventional structures scored poorly in both sectors. Team structures reported stronger communications systems in public libraries than academic libraries. 
Table 2 sets out the overall results for the average number of documentation types made available and the average number of communication channels identified.

\begin{tabular}{|l|l|l|l|l|}
\hline & $\begin{array}{l}\text { Matrix } \\
\text { Structures }\end{array}$ & $\begin{array}{l}\text { Flattened } \\
\text { Structures }\end{array}$ & $\begin{array}{l}\text { Team } \\
\text { Structures }\end{array}$ & $\begin{array}{l}\text { Conventional } \\
\text { Structures }\end{array}$ \\
\hline Documentation Types & 7.38 & 5.35 & 5.19 & 3.44 \\
\hline Information Channels & 5.38 & 5.44 & 4.8 & 3.3 \\
\hline
\end{tabular}

Table 2 Communication and organisational Structures

The relevant questions for this section of the questionnaire invited respondents to identify the availability of 15 kinds of information, and eight communication channels.

A mixed picture was also reflected in other ways. For the purposes of the questionnaire, communication was deemed satisfactory if an organisation disseminated information in more than $50 \%$ of the 12 categories itemised. This criterion was met in $45 \%$ of the organisations responding. A $71 \%$ rating was achieved by the highest performer.

It was quite common to find organisations placing embargoes on budgetary information, which could open up an interesting debate, but what was more surprising was a general absence of systematic attempts to disseminate:

- Information about good practice

- The results of special projects

- Any organisational lessons learned

Whether this is due to a policy decision or to the absence of procedures to quantify and make this information available is worth further investigation.

The methods of communication used were unimaginative. Only $30 \%$ of organisations made satisfactory use of a wide range of communication channels, with some evidence of a lack of awareness of the power of informal communication, and certainly of what one respondent in the pilot study termed the "formal informal communication system."

\section{The Delivery of Electronic Resources}

Participants in the survey were invited to identify the methods of acquring, managing, storing, and presenting information in different formats. Delivery of electronic resources to users was considered to be wholly integrated, or as part of a division dealing also with conventional resources, with no distinction between forms of information at any stage, in $85 \%$ of the libraries involved.

The management of electronic resources is predominantly seen as the responsibility of a generalist, with $85 \%$ of library services viewing this as the responsibility of a manager with significant other responsibilities, and only $15 \%$ regarding it as an area for a specialist manager.

The physical integration of formats is still an area where perhaps much remains to be done, with only $5 \%$ of respondents considering their physical integration of formats to be significant. The picture remained much the same for the range of material accessible to users in one physical location.

\section{Staff Development and Organisational Learning}

This general area is identified in the literature as critical to organisation development. Out of the organisations covered in this segment of the research, $25 \%$ had no formal staff development policy. In one case, a staff development policy existed for senior management only.

Formal policies for organisational learning and learning from work were only identifiable in $35 \%$ of organisations. In only a handful of cases was there an acknowledgment of the need to understand how to learn from work, and how to apply lessons learned in work situations.

Self-development, once described as "the classic training cop-out", not surprisingly was universally supported. But once again, the follow up question offering a menu of ways in 
which self-development was supported produced some negative results:

- $70 \%$ of replies indicated that some support for self development was provided

- Out of the 13 options offered as forms of support, with $50 \%$ considered to be a satisfactory response, the highest scoring institution reached $69 \%$

- Organisations providing support for self development used on average 4.86 methods of providing this support

\section{Human Resource Issues}

Structural change should also enable the application of skills and the use of talents in a more imaginative and appropriate way. There is little point in acquiring new skills, and enlarging and enriching jobs, if there is insufficient flexibility to allow these skills to be applied wherever relevant in the organisation.

Job descriptions are one way of facilitating this flexibility. They are also signs of general organisational flexibility. Respondents were invited to express their views on the statement that job descriptions in their organisations were precise and well-defined. Once again, the majority of respondents neither agreed nor disagreed with the proposition.

- $20 \%$ felt that they were flexible and illdefined, implying some freedom.

A similar question asked for a response to the proposition that staff who acquired new skills would find it easy to gain promotion or to move to another part of the library where the skills could be used.

- This was felt to be neither easy nor difficult in $75 \%$ of cases

- Where it was identified as difficult, it was considered to be very difficult, and in these cases there was a correlation with below-par team development.

\section{Skills}

Respondents were asked to identify, and rank in order of importance, a number of skills they considered necessary for library staff. All identified customer service and interpersonal skills as essential. A slightly smaller number identified team working skills.

The importance attached to teamworking is theoretically understandable, but raises issues in the light of the preceding analysis of the extent of the team building in the organisations involved in the research. All of the organisations considered themselves to be team based, yet only $25 \%$ actually reported team characteristics which indicated a substantial degree of development and a clear move towards empowered, self managing teams. A typical comment when asked to indicate how much responsibility teams exercised was "It depends on the level at which the team operates."

The other element of note is the overwhelming importance of what are sometimes called the "softer skills" of customer service and interpersonal relationships. This is supported by the continued importance attached to the skills of traditional reference work and promotion.

Managers who identified the skills of customer services and interpersonal relationships as being of primary importance, also affirmed the primary importance of leaders in creating an environment in which people could work to their maximum ability. Some also indicated the possibility of role changes at several levels:

The role of front line staff has changed significantly, and we are re-directing resources to deal with this. .... Middle management numbers have been reduced to increase levels of front line staff.

No major significance was attached to the skills of creating metadata, and the ability to promote the library service was ranked equal with the skills of web and Internet searching. 


\begin{tabular}{|c|c|c|c|c|}
\hline \multirow[t]{2}{*}{ Skill } & \multicolumn{4}{|c|}{ \%age of respondents attaching significance } \\
\hline & $0 \quad 25$ & 50 & 75 & 100 \\
\hline \multicolumn{5}{|l|}{ Customer service } \\
\hline \multicolumn{5}{|l|}{ Interpersonal skills } \\
\hline \multicolumn{5}{|l|}{ Teamworking } \\
\hline \multicolumn{5}{|l|}{$\begin{array}{l}\text { Promotion } \\
\text { Web searching }\end{array}$} \\
\hline \multicolumn{5}{|l|}{ Traditional reference skills } \\
\hline \multicolumn{5}{|l|}{ Presentation skills } \\
\hline Web editing & ב & & & \\
\hline Written communications & & & & \\
\hline Language skills & 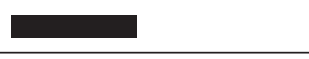 & & & \\
\hline $\begin{array}{l}\text { Metadata } \\
\text { Pedagogy }\end{array}$ & & & & \\
\hline
\end{tabular}

Table 3: Skills Requirements

\section{Leadership}

\begin{tabular}{|l|ll|}
\hline Skill & \%age of respondents attaching significance \\
\hline & 0 & 25 \\
\hline Creating the right environment & & \\
\hline Setting strategy & & \\
\hline Political skills & & \\
\hline Planning skills & & \\
\hline Role model & & \\
Innovative thinking & \\
\hline Problem-solving & \\
\hline Negotiation & \\
Collaboration & \\
\hline Promotional skills & \\
\hline Mentoring & \\
\hline Conflict management & \\
\hline Control & \\
\hline Coaching & \\
\hline
\end{tabular}

Table 4: Desirable Leadership Skills

The significance attached to various leadership characteristics, as indicated in Table 4, reflects a conventional view. Strategy-setting, political skills, and planning were seen as more significant than other skills such as negotiating, conflict management, innovative thinking, and coaching. This offers another interesting perspective on organisation development in library services. The emphasis on these managerial aspects could arguably reflect the position taken in an earlier question, where $65 \%$ of respondents saw strategy formulation as a responsibility which would rest primarily with senior management. Ideas about sophisticated forms of responsibility-sharing, common in management literature, are less evident in 
professional practice as reflected in the replies to the questionnaire. The literature of librarianship also refers to distinctions between strategic and operational teams, while the literature of general management refers to various ways of broadening inputs into strategy.

The predominant organisational picture painted by the data suggests organisations where there is still an inability or unwillingness to open up the procedure of setting strategy. This is confirmed by the absence of open management information systems as well as the view of desirable leadership skills.

\section{Organisational Learning and Professional Development}

$65 \%$ of respondents reported no formal policies to cover organisational learning and learning from work. Support for self development is also a factor to consider in this respect.

\section{Changing Roles}

The final section of the questionnaire asked respondents to consider how, if at all, the roles of senior and middle managers had changed as a result of the development of digitisation and hybrid libraries in general. These responses are indicated below.

Overall, the response indicates a generally conventional approach to the attributes of leadership.

\begin{tabular}{|l|l|l|l|l|}
\hline \multicolumn{5}{|c|}{ Degree of Change } \\
\hline & Significant & Moderate & Limited & None \\
\hline Senior Management & $19 \%$ & $38 \%$ & $38 \%$ & $5 \%$ \\
\hline Middle Management & $38 \%$ & $38 \%$ & $13 \%$ & $11 \%$ \\
\hline
\end{tabular}

Table 5: Degree of change in senior/middle management roles

Change in the roles of middle management is rated as moderate to significant in $76 \%$ of organisations. This group is one of the keys to development, because their capacity for role change and growth will be a factor in the development of leadership and effective teams. $57 \%$ of organisations also reported significant or moderate change in the roles of senior management.

There are indications in some of the additional written responses that these changes are leading to increases in front line staff, with reductions in the number of middle managers reported in $35 \%$ of cases, and those reductions being either limited or moderate in extent.

\section{Conclusions}

While it is difficult to identify a working model of hybrid library organisations which reflects a coherent, methodical, and sustained approach to organisational development, and which takes into account the crucial environmental influences at work on hybrid libraries, there is some evidence of:
- Work on structural change

- A developing but partial understanding of the significance of teams

- A particularly acute awareness of the need to reaffirm the human skills of customer services and interpersonal relationships in a technological environment

- A major weakness in organisational learning

The full report, The Organisational Design and Development of Hybrid Libraries: Structures, Leadership, Management Styles and Philosophy, Professional and Personal Development, is available from LIRG. 


\section{Bibliography}

Allee, V.The Future of Knowledge: Increasing Prosperity Through Value Networks. New York, Elsevier Science, 2003.

Ashcroft, L. Developing competencies, critical analysis and personal transferable skills in future information professionals. Library Review, vol 53 no 22004.

Ashworth,W. Organising multi-site libraries. LACTFE, 1976.

Augar, P., and Palmer, J.The rise of the player manager: how professionals manage while they work. Penguin, 2002.

Bailey, K. M., Curtis, A., and Nunan, D. Pursuing professional development: the self as source. Heinle and Heinle, 200I.

Brickley, J. A., Smith, C.W., Willet, J., and Zimmerman, J. L. Designing organizations to create value: from strategy to structure. McGraw-Hill, 2003.

Bryson, J. Effective Library and Information Centre Management. 2nd ed. Aldershot, Gower, 1999.

Bucknall, T.Techno teamwork: involving all staff in library automation. In North Carolina Libraries 54 (4) 1996.

Cloke, K., and Goldsmith, J. The end of management and the rise of organizational democracy. John Wiley \&Sons, 2002.

Coing, M. Effective communication: an essential tool to cope with the challenge of technological change: the German Bundestag Library example. Inspel vol 35 no 2 2001.

Cross, R., and Parker, A. The hidden power of social networks. Harvard Business School Publishing, 2004.

Deegan, M., and Tanner, S. Digital futures: strategies for the digital age. LAPL, 2002.

Drucker, P. F.What makes an effective executive. Harvard Business Review Vol. 82, No. 6 June 2004.

Echt, R. The reality of teams in technical services at Michigan State University Libraries. In Library Acquisitions Practice and Theory, 2 I (I) 1997.

Eckwright, G. Z., and Brolin, M. K. The hybrid librarian: the affinity of collection management with technical services and the organizational benefits of an individual assignment. Journal of Academic Librarianship, vol 27 no6 November 200I.

Glass, N. Management masterclass: a practical guide to the new realities of business. Nicholas Brealey, 1996.

Gorman, M. On doing away with technical services departments. In American Libraries 10 July-August, 1979Prytherch, R. The literature review: state of the sector project. Library and Information Commission Research Report 126. 2002.
Library \& Information Research (LIR)

Volume 29 - Number 92 - Summer 2005

Hirshberg, J. The creative priority: driving innovative business in the real world. Penguin, 1998.

Lorsch, J.W., and Mathias, P. F.When professionals have to manage. Harvard Business Review, July-August 1987.

Lynch, B. (ed.) Management strategies for libraries: a basic reader. New York, Neal-Schuman Publishers Inc., 1985.

Malone, T.W.The future of work: how the new order of business will shape your organization, your management style, and your life. Harvard Business School Press, 2004.

Martell, C. The client-centered academic library. Greenwood Press, 1983.

Pugh, L. C. Convergence in academic support services. British Library Research and Innovation Report, British Library, 1997.

Mauzy, J., and Harriman, R. Creativity, inc: building an inventive organization. Harvard Business School Press, 2003.

Mcllwaine, A. Changing the culture: the Change Management Programme at UCL. SCONUL Newsletter 24, Winter 2001.

Morgan, G. Images of organization. New ed. Sage, 1997.

Owen, $\mathrm{H}$. Leading the way in the way of leadership.

Western Mail, 27th January $200 \mathrm{I}$.

Owen, H. Creating top flight teams. Kogan Page, 1996.

Pasternak, B., and Viscio. A. J. The centerless corporation: a new model for transforming your organization for growth and prosperity. Simon and Schuster, 1998.

Pearn, M., and Mulrooney, C. Tools for a learning organisation. Institute of Personnel and Development, 1995.

Pearn, M., Roderick, C. and Mulrooney, C. Learning organizations in practice. McGraw- Hill, 1995.

Powell, M. Designing library space to facilitate learning: a review of the UK higher education sector. Libri vol 52 no 22002.

Pugh, L. C. Change management in information services. Gower, 2000.

Pugh, L. C. Leadership and learning: helping librarians reach their potential. Scarecrow Press, 200I.

Pugh, L. C The management of innovation in public sector higher education learning resources provision. Leeds Metropolitan University M.Phil thesis, 1990.

Pugh, L. C. The management of 2 Ist century libraries. Scarecrow Press, 2004.

Pugh, L. C. Organizational structures in converged information services. Unpublished small scale research project, February 2002.

Robbins, S. Organizational learning is no accident. HBS Working Knowledge Newsletter, May 19, 2004. 
Roitberg, N. The influence of the electronic library on library management: a technological university library experience. IFLA Journal vol 27 no I, 200I.

Schmidt, W. D., and Rieck. D. A. Managing media services: theory and practice. 2nd ed. Libraries Unlimited, 2000.

Stueart, R. D., and Moran, B. B. Library and information center management. 6th ed. Libraries Unlimited, 2002.

Sutton, R. The weird rules of creativity. Harvard Business Review, vol 79 no 8 September 200I.

Tomke, S. Enlightened experimentation: the new imperative for innovation. Harvard Business Review, February 2001. 